\title{
Dendritic Transport
}

\section{Colchicine Stimulates the Transport of Lysosomal Enzymes from Cell Bodies to Dendrites ${ }^{1}$}

\author{
CHARLES GORENSTEIN, ${ }^{2}$ MARSHA C. BUNDMAN, PAULINE J. LEW, JAMES L. OLDS, AND \\ CHARLES E. RIBAK*
}

Departments of Pharmacology and * Anatomy, University of California, Irvine, Irvine, California 92717

\begin{abstract}
Injection of colchicine into the lateral cerebral ventricle of the rat was found to induce a paradoxical translocation of two lysosomal enzymes, dipeptidyl peptidase II (Dpp II) and acid phosphatase, from the soma of neurons to the dendrites. Following a single injection of colchicine, neuronal somata, which normally contain the bulk of these lysosomal enzymatic activities, become depleted of these enzymes, whereas dendrites become abnormally enriched. All neurons which contained these enzymes, except those of the mesencephalic nucleus of the trigeminal nerve, displayed this phenomenon. Lysosomal enzyme translocation into dendrites was observed in the mitral cell layer within $1 \mathrm{hr}$ after a colchicine injection and could be induced in most neuronal populations by injections of colchicine as low as $25 \mu \mathrm{g}$. Five days after a $100-\mu \mathrm{g}$ colchicine injection, a normal pattern of enzyme distribution was observed, indicating that the effect of colchicine was reversible. Enzyme translocation was not accompanied by gross changes in cell morphology, nor did it result in the specific loss of neuronal cell bodies which contained these enzymes. The results indicate that colchicine, under conditions known to inhibit axoplasmic transport, stimulates the transport of lysosomal enzymes from the cell body to the dendrites.
\end{abstract}

Neurons, by virtue of their unique architecture, have developed specific transport systems to regulate the flow of materials from the cell body to distal regions in the axon and dendrites. Numerous studies indicate the presence of a bidirectional flow of cellular constituents between the soma, the axon, and the dendrites that is mediated by cytoskeletal elements such as microtubules, intermediate filaments, and neurofilaments (for reviews see Grafstein and Forman, 1980; Ochs, 1984). Although transport in axons has been a well documented phenomenon, comparatively few studies have addressed the issue of transport in dendrites. This could be due to: (1) the difficulties encountered when measuring flow along a complex branching pattern of dendrites, (2) the small size of dendrites preventing classical ligature and lesion experiments, and (3) the

Received August 22, 1984; Revised December 19, 1984;

Accepted January 2, 1985

\footnotetext{
${ }^{1}$ This work was supported by National Institute of Drug Abuse Grant DA 03131 and National Institutes of Health Grant NS 18994 to C. G. We thank Drs. Larry Stein and James Fallon for a careful reading of the manuscript.

${ }^{2}$ To whom correspondence should be addressed.
}

complexities introduced by the presence of ribosomes in the larger dendritic branches near the cell body, where presumably protein synthesis could take place.

Dendritic transport has been studied by means of intracellular injections of radiolabeled precursors combined with autoradiography. Iontophoretic injections of ${ }^{3} \mathrm{H}$-glycine into motoneurons of the spinal cord produce a pattern of labeling consistent with the fast transport of proteins from the soma to the dendrites (Globus et al., 1968). The labeling patterns observed after injections of precursors such as ${ }^{3} \mathrm{H}$-leucine, ${ }^{35} \mathrm{~S}$-sulfate, ${ }^{3} \mathrm{H}$-choline, and ${ }^{3} \mathrm{H}$-orotic acid are also compatible with fast and slow dendritic transport of proteins, glycoproteins, acid mucopolysaccharides, phospholipids, and RNA (Kreutzberg and Schubert, 1973, 1975; Kiss, 1977). Evidence for the rapid bidirectional transport of proteins in dendrites has also been obtained from in vitro horseradish peroxidase injections into cell bodies or dendrites of pyramidal neurons in the hippocampal formation of the rat (Lynch et al., 1975). Dendritic transport, like that in axons, can be blocked by colchicine and similar drugs which disrupt microtubule polymerization (Schubert et al., 1972). Thus, it appears that dendritic transport shares in common many of the properties described for axonal transport

The effects of colchicine on nervous tissue have attracted considerable attention, since this drug blocks axonal transport but does not interfere with protein synthesis (James et al., 1970). Thus, injections of colchicine cause enzymes and organelles that are normally transported to nerve terminals to accumulate in the cell body and proximal dendrites (Fonnum et al., 1973; Ribak et al., 1978; Grafstein and Forman, 1980). As a resull, colchicine injeclions have proved invaluable in the localization of normally undetectable peptides and enzymes with immunocytochemical methods (Ribak et al., 1978; innis et al., 1979).

In a previous study we showed that dipeptidyl peptidase II (E.C. 3.4.14.2; Dpp II), an acid peptidase which cleaves two amino acids from the amino terminal end of peptides, was highly localized to a small number of neuronal populations in the rat brain (Gorenstein et al., 1981). Intense staining, mainly associated with cell bodies and to a lesser extent with dendrites, was observed in the mitral cell layer of the olfactory bulb, anterior dorsal nucleus of the thalamus, mesencephalic nucleus of the trigeminal nerve, red nucleus, central nucleus of the inferior colliculus, inferior olivary nucleus, stratum album of the superior colliculus, and Purkinje cells and deep nuclei of the cerebellum. In an attempt to enhance the visualization of this enzyme in all neuronal populations, including those with low Dpp II activity, we reasoned that intracerebroventricular injections of colchicine would produce a detectable enrichment of Dpp II in cell bodies. In this paper we report a paradoxical effect of colchicine on the intraneuronal localization of two lysosomal enzymes: Dpp II and acid phosphatase. 

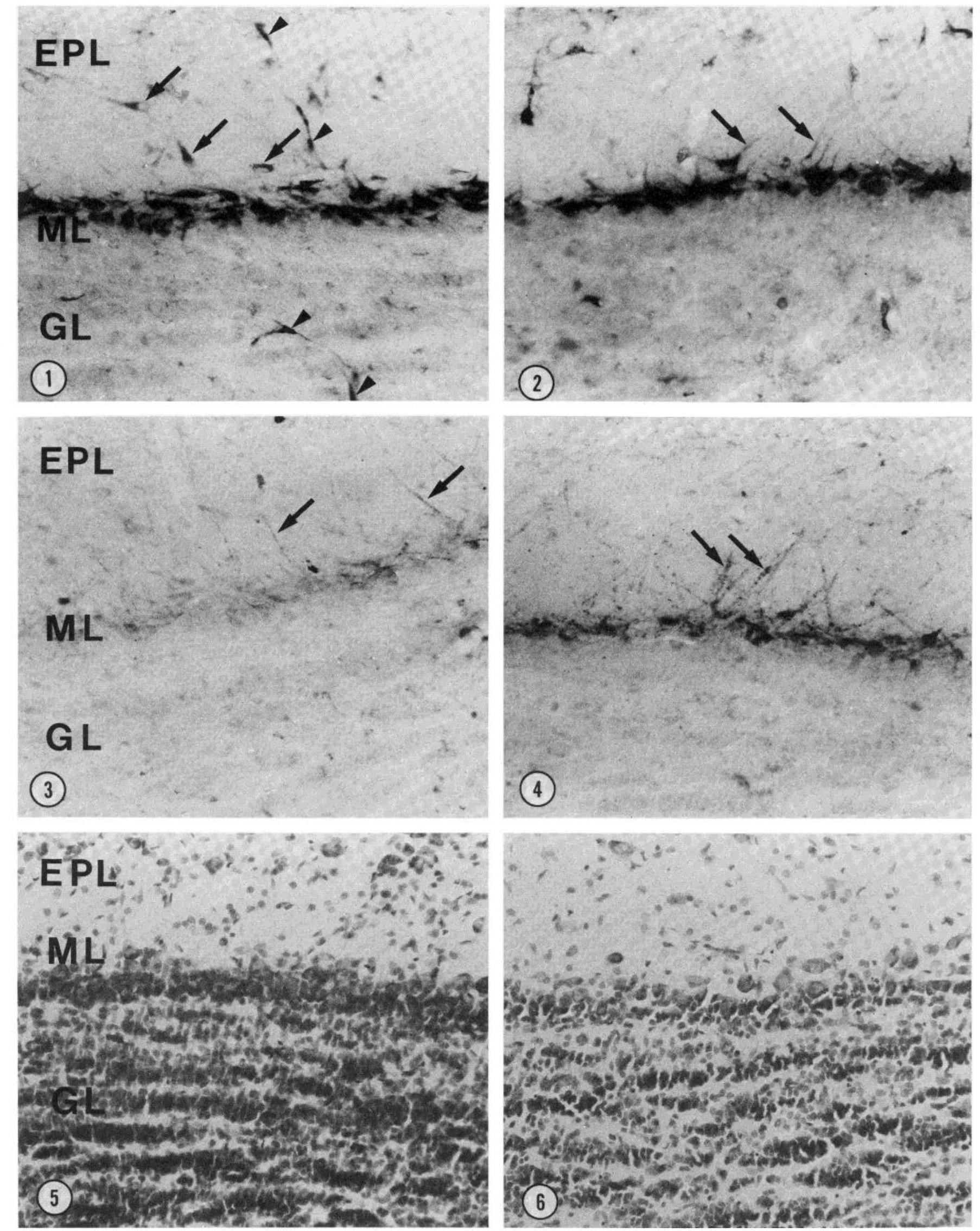

Figures 1 to 4 . Sagittal sections through the olfactory bulb showing the effects of colchicine on the histochemical distribution of Dpp II. Figure 1 shows the histochemical localization of Dpp II in saline-injected animals. Intense somal staining in the mitral cell layer $(M L)$ is clearly visible. Some tufted cells in the external plexiform layer (EPL) are also positive for Dpp II (arrows). In the external plexiform layer and the granule cell layer (GL) it is possible to observe Dpp II-positive pericytes associated with blood vessels (arrowheads). Figure 2 shows the effect of a $100-\mu \mathrm{g}$ colchicine injection with a survival time of $1 \mathrm{hr}$. Note 


\section{Materials and Methods}

Drug injections. Male Sprague-Dawley rats were deeply anesthetized with pentobarbital and their heads were placed in a stereotaxic apparatus. A microsyringe was placed with its tip in the lateral cerebral ventricle using coordinates obtained from the atlas of Koning and Klippel (1963). Various concentrations of colchicine and other cytoskeletal specific drugs, dissolved in 10 to $30 \mu \mathrm{l}$ of saline, were injected intracerebroventricularly (i.c.v.). Animals were allowed to recover for various periods of time, and their brains were processed for histochemistry as described below.

Histochemical localization of Dpp II. Rats were deeply anesthetized with pentobarbital and perfused intracardially with a solution containing $4 \%$ formaldehyde in $50 \mathrm{~mm}$ phosphate buffer at $4^{\circ} \mathrm{C}$ for $15 \mathrm{~min}$. The brain was rcmoved, stripped of its meninges, hemisected, and glued with cyanoacrylate to the stage of a Vibratome (Oxford Instruments). A solution containing $2 \%$ low-temperature agarose (FMC Corporation) at $37^{\circ} \mathrm{C}$ was poured around the brain and allowed to solidify at room temperature; this provided mechanical support during sectioning. Sagittal sections, $50 \mu \mathrm{m}$ thick, were cut and placed in ice-cold $0.1 \mathrm{M}$ sodium acetate buffer, $\mathrm{pH} 5.0$.

Dpp II activity was visualized by incubating the brain slices at $37^{\circ} \mathrm{C}$ for 60 $\mathrm{min}$, in a solution containing $1 \mathrm{mg} / \mathrm{ml}$ of lysyl-alanyl-4-methoxy- $\beta$-naphthylamide (Lys-Ala-MNA), $1 \mathrm{mg} / \mathrm{ml}$ of fast blue B (Serva Biochemicals), dissolved in $0.1 \mathrm{M}$ sodium acetate, $\mathrm{pH} 5.0$. Under these conditions, Dpp II reacts specifically with Lys-Ala-MNA to liberate free MNA and the dipeptide LysAla. Free MNA reacts rapidly with the a7o dye, fast blue $B$, to produce an insoluble and highly colored precipitate marking the sites which contain Dpp II activity. The histochemical reaction was terminated by rinsing the brain slices in saline, and the colored reaction product was intensificd and stabi lized by treating the slices with $0.1 \mathrm{M} \mathrm{CuSO}_{4}$ for 1 min. Sections were mounted on glass slides, air dried, and coverslipped in Permount (Fisher Scientific). As the reaction product bleaches in strong light, sections were stored at $4^{\circ} \mathrm{C}$ in covered boxes until ready to be photographed. In all cases where Dpp If histochemistry was performed, adjacent slices were stained with cresyl violet.

Histochemical localization of acid phosphatase. Acid phosphatase localizations were prepared according to the metal salt procedure essentially as described by Gomori (1952), using 2-glycerophosphate as the substrate and lead nitrate as the capturing agent. Sections were washed in saline and intensified in ammonium sulfide prior to mounting and coverslipping with Permount.

In vitro effect of colchicine. Rat brains obtained by decapitation were homogenized in $15 \mathrm{vol}$ of ice-cold $0.1 \mathrm{M}$ sodium acetate, $\mathrm{pH}$ 5.0. The homogenate was spun at $50,000 \times g$ for $20 \mathrm{~min}$, and the supernatant which contained over $95 \%$ of the total Dpp II activity was saved. Dpp II activity was assayed fluorometrically by measuring the release of $\beta$-naphthylamine (NA) from lysyl-alanyl- $\beta$-naphthylamide (Lys-Ala-NA). Reaction mixtures in a total volume of $100 \mu \mathrm{l}$ contained $10 \mu \mathrm{l}$ of soluble brain extract, $0.1 \mu \mathrm{mol}$ of Lys Ala-NA, $10 \mu \mathrm{mol}$ of sodium acetate, $\mathrm{pH} 5.0$, and various concentrations of colchicine dissolved in water. Incubations were carried out at $37^{\circ} \mathrm{C}$ for 30 $\mathrm{min}$ and stopped by placing in a boiling water bath for $1 \mathrm{~min}$. The volume of the reaction mixture was adjusted to $1 \mathrm{ml}$ with $1 \mathrm{M}$ Tris, $\mathrm{pH} 8.0$. Fluorescence was determined in an Aminco-Bowman fluorometer (ex., $340 \mathrm{~nm}$; emm., 410 $\mathrm{nm}$ ). Since colchicine quenches the fluorescence of NA, appropriate quench controls using free NA and colchicine as standards were carried out.

\section{Results}

Normal staining pattern of Dpp /I. In the brain, Dpp II reaction product is localized to a siriall number of neuronal populations. Although the majority of the enzyme activity appears to be localized in neurons, a significant fraction is localized in pericytes associated with small blood vessels (Fig. 1, arrowheads). Within neurons, granular deposits representing Dpp II activity are uniformly distributed throughout the cytoplasm and are not found over the cell nucleus. On occasion, a dendrite appeared labeled in regions near the cell body. Axons were never seen to contain Dpp II.
A number of brain regions display Dpp II staining; a few representative examples are described here for comparison with the data obtained from colchicine preparations. In the olfactory bulb (Fig. 1) intense Dpp II staining is observed in the perikarya of cells found in the mitral cell layer. In addition, occasional tufted cells in the external plexiform layer and pericytes in all layers were positive for Dpp II (Fig. 1). In the cerebellar cortex, Purkinje cells and pericytes stain positively for Dpp II (Fig. 7). In the medulla a number of neuronal nuclei stain positively for Dpp II; i.e., the nucleus ambiguus (Fig. 9), the superior olivary complex (Figs. 11 and 12), and the lateral reticular nucleus (Fig. 18). In the midbrain, Dpp If staining occurs in the perikarya of magnocellular neurons of the red nucleus, with less intense staining in the neurons of the parvocellular region (Fig. 15). The mesencephalic nucleus of the trigeminal nerve and the subceruleus also display intense perikaryal staining for Dpp II (see Fig. 22) In addition to these results, similar data were obtained for other brain regions which we previously reported to contain Dpp || (Gorenstein et al., 1981).

Effect of colchicine on the localization of Dpp II. In an attempt to produce an accumulation of enzyme within cell bodies of neurons with low Dpp Il activity, we utilized i.c.v. injections of colchicine. In uninjected and saline-injected control rats, the cellular localization of Dpp II displays the same pattern of labeling as described above. However, when neurons were examined in colchicine-treated animals, we noted that colchicine induced an unexpected redistribution in the intraneuronal pattern of Dpp II staining (Fig. 4). Thus, the mitral cells display a decrease of somal staining with a concomitant increase in dendritic staining (cf. Fig. 1). In the external plexiform layer, primary as well as secondary mitral cell dendrites now contain Dpp II rcaction product. In addition to this phenomenon, colchicine produces a selective loss of granule cells from the granule cell layer without any obvious effects on the mitral cells (cf. Figs. 5 and 6 ). It is interesting to note that the granule cells which normally contain little or no Dpp II reaction product are not stained in these colchicine preparations.

A similar redistribution of Dpp II staining is observed in virtually all neurons which contain the enzyme. In the presence of colchicine, dendrites become enriched with Dpp II whereas cell bodies become depleted of the enzyme. For example, in the cerebellar cortex, Purkinje cells which normally contain high concentrations of Dpp ॥ in the cell body (Fig. 7) display Dpp II in a polarized distribution, concentrated on the cellular pole from which dendrites arise (Fig. 8). Moreover, numerous dendrites that extend into the molecular layer also contain Dpp II reaction product in these colchicine preparations (Fig. 8).

Other examples which exemplify this unusual phenomenon are the dendrites of the nucleus ambiguus (Figs. 9 and 10) and the superior olivary nucleus (Figs, 13 and 14). In these cases, colchicine produces a near depletion of enzyme in cell bodies and permits the visualization of large portions of the dendritic arbor. In contrast, other brain regions display a more heterogeneous response to colchicine; for example, in the red nucleus the magnocellular neurons display intense dendritic and somal staining, whereas the parvocellular neurons show mainly dendritic staining (Fig. 16)

A notable exception to the redistribution of Dpp II occurs in the mesencephalic nucleus of the trigeminal nerve. In this group of neurons colchicine has no effect on the degree of Dpp II somal staining (cf. Figs. 22 and 23). It is interesting to note that these neurons comprise the only population of pseudo-unipolar neurons in the brain and therefore lack dendrites.

that the mitral cell dendrites (arrows) now contain Dpp II reaction product. Figure 3 shows the effects of a 100- $\mu$ g colchicine injection with a survival of 3 hr. Mitral cell bodies are nearly devoid of Dpp II reaction product. Dendrites (arrows) extending into the external plexiform layer are labeled extensively with Dpp $\|$. Figure 4 shows the effect of a 100- $\mu \mathrm{g}$ injection of colchicine with a survival time of $24 \mathrm{hr}$. Mitral cell bodies in the ML are labeled, but to a lesser extent than that seen in Figures 1 and 2. Dendrites (arrows) are extensively labeled with Dpp || reaction product and can be followed for a considerable distance into the external plexiform layer. Magnification $\times 175$ for Figures 1 to 4 .

Figures 5 and 6 . Effect of colchicine on the morphology of the olfactory bulb. Figure 5 shows the normal Nissl-stained appearance of a brain section adjacent to that seen in Figure 1. Figure 6 shows a Nissl-stained section adjacent to that seen in Figure 4 and demonstrates the loss of granule cells from the granule cell layer $(G L)$ after a $100-\mu \mathrm{g}$ colchicine injection with a survival time of $24 \mathrm{hr}$. Magnification $\times 175$ for Figures 5 and 6 . 

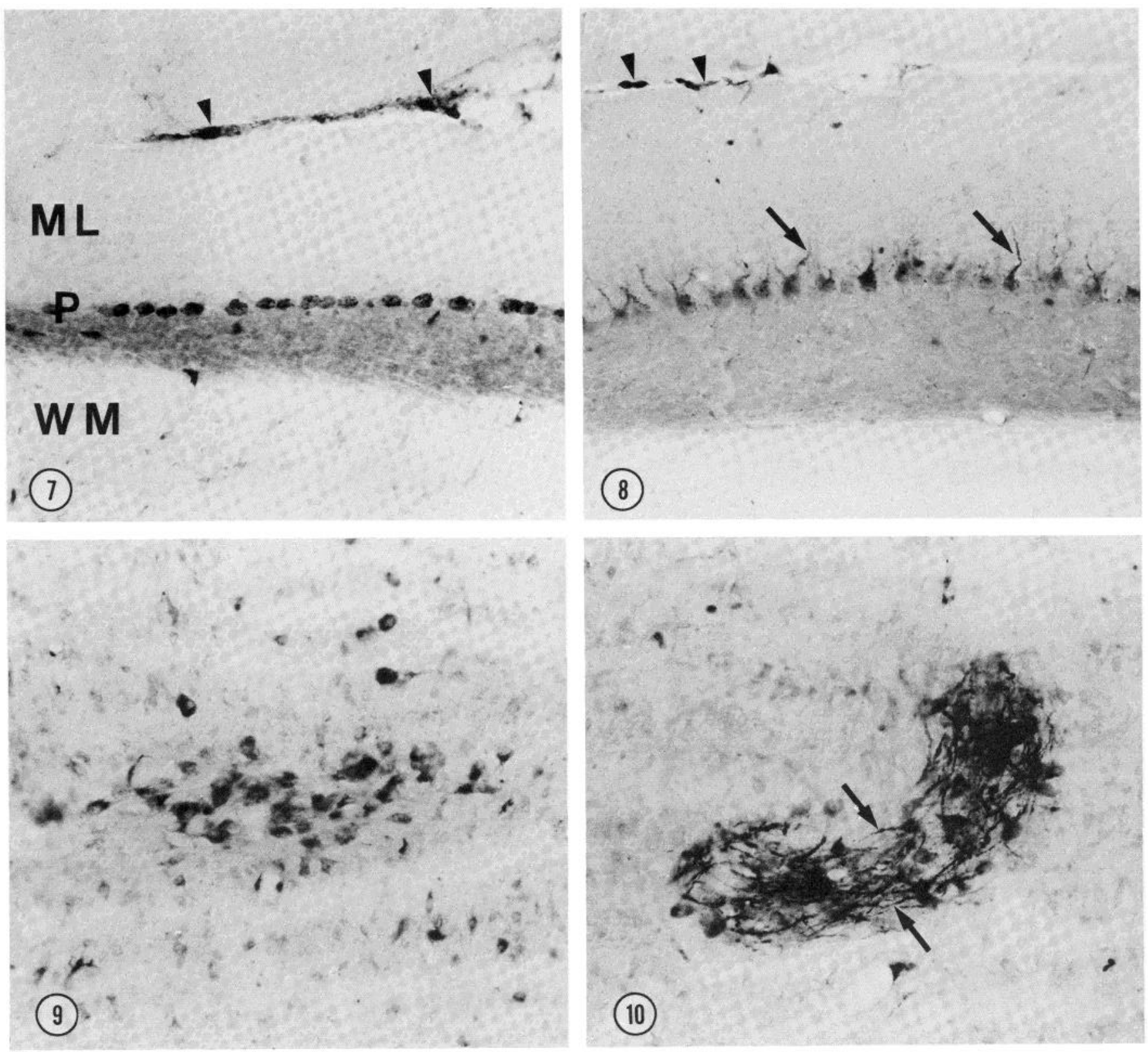

Figures 7 and 8. Sagittal sections through the cerebellar cortex showing the histochemical localization of Dpp II. Figure 7 shows the distribution of Dpp II in a control animal. Intense staining in the Purkinje cells $(P)$ and in blood vessels at the pial surface (arrowheads) is apparent. Diffuse staining is also visible in the granule cell layer between the Purkinje cell layer and white matter (WM). Figure 8 shows the effect of a 100- $\mu \mathrm{g}$ colchicine injection with a survival time of $24 \mathrm{hr}$. Intense Dpp \|| reaction product is now visible in Purkinje cell dendrites (arrows) extending into the molecular layer (ML). Magnification $\times 175$ for Figures 7 and 8.

Figures 9 and 10. Effect of colchicine on the histochemical distribution of Dpp II on the nucleus ambiguus of the medulla. Figure 9 shows the distribution of Dpp II in a control section. Note that the staining is confined mainly to cell perikarya. Figure 10 demonstrates the effect of a $100-\mu \mathrm{g}$ colchicine injection with a 24 -hr survival. Note that the intense dendritic staining (arrows) gives this nucleus an apparent crescent shape and outlines its boundaries. Magnification $\times 175$ for Figures 9 and 10 .

Kinetics of Dpp II redistribution in the olfactory bulb. Following an i.c.v. injection of $100 \mu \mathrm{g}$ of colchicine, it is possible to detect a redistribution of Dpp $\|$ as early as $1 \mathrm{hr}$. This can be clearly seen in the mitral cell layer of the olfactory bulb (Fig. 2). Three hours after the colchicine injection, marked dendritic staining that extends into the external plexiform layer is visible, and there is a drastic decrease in somal Dpp II staining (Fig. 3). Twenty-four hours after a colchicine injection, somal Dpp II staining reappears and dendrites remain stained (Fig. 4),

The dendritic staining observed in response to colchicine is reversible; however, different brain regions have variable responses.
Recovery is best seen in neurons of the red nucleus. Twenty-four hours after a $100-\mu \mathrm{g}$ colchicine injection there is dense Dpp II reaction product in both cell bodies and dendrites (Fig. 16). In contrast, 5 days after the colchicine injection only somal staining is observed (Fig. 17).

Dose response of colchicine. The effect of different concentrations of colchicine on the redistribution of Dpp II was studied in neurons of the lateral reticular nucleus of the medulla. Increasing the dose of colchicine between 25 and $400 \mu \mathrm{g}$, and a survival time of $24 \mathrm{hr}$, results in an increased density of Dpp $\|$ reaction product in dendrites (Figs. 18 to 21). At the lowest dose of colchicine, somal 

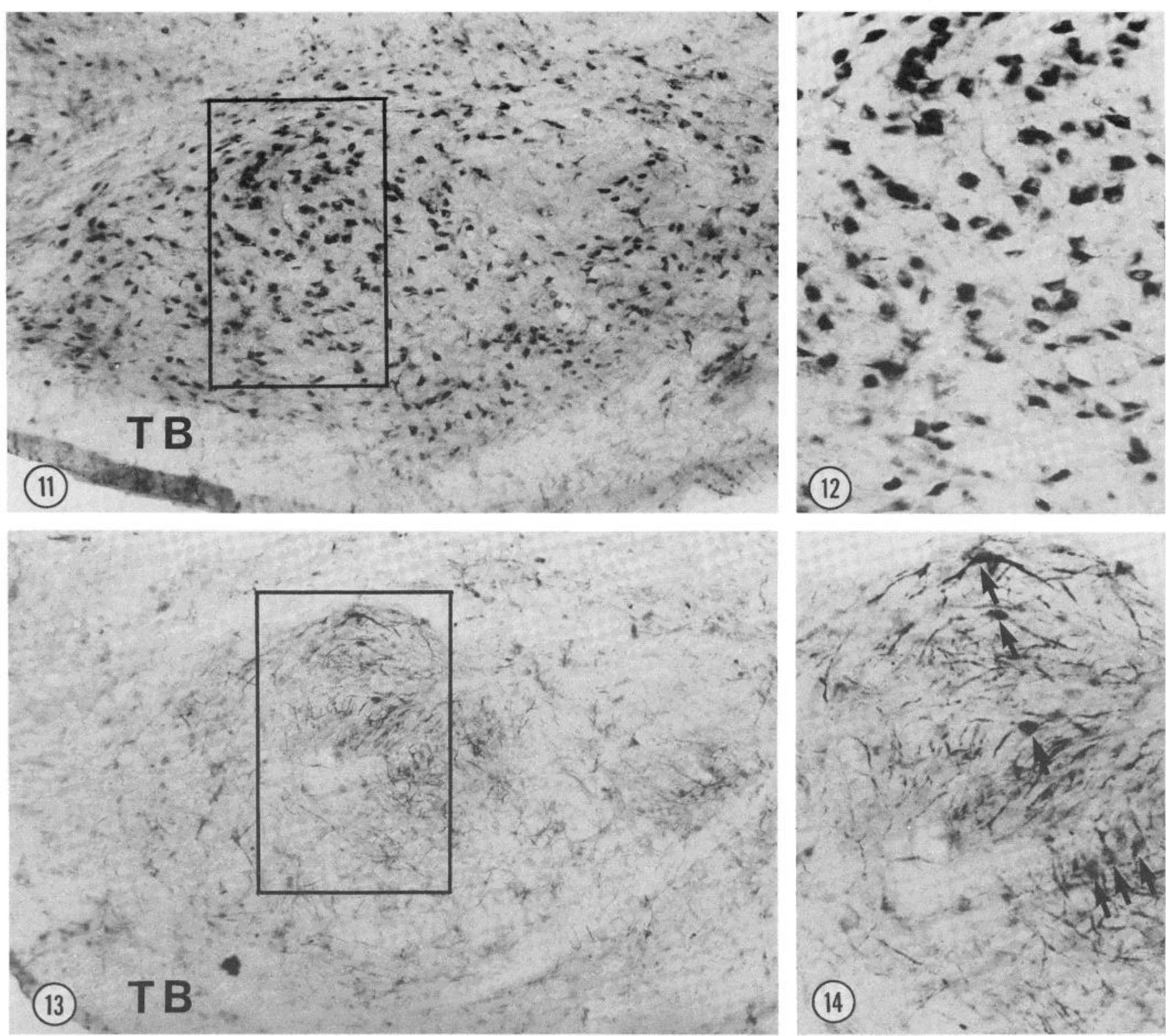

Figures 11 and 12. Sagittal section from a control animal showing the distribution of Dpp II in the superior olivary complex. In Figure 11 the unlabeled white matter bundle on the ventral surface of this nucleus is the trapezoid body (TB). Magnification $\times 87$. Figure 12 is an enlargement of the box delineated in Figure 11. Note the dense staining of somata for Dpp II reaction product. Magnification $\times 175$.

Figures 13 and 14. Effect of an i.c.v. injection of $100 \mu \mathrm{g}$ of colchicine with a 24-hr survival time on the distribution of Dpp II in the superior olivary complex. Figure 13 shows that numerous dendrites containing Dpp II reaction product are visible throughout this nucleus. Magnification $\times 87$. Figure 14 is an enlargement of the box delineated in Figure 13. Note that only a few cell bodies (arrows) remain labeled after colchicine treatment. Magnification $\times 175$.

Dpp II staining predominates (Fig. 19), whereas at the highest dose it is completely abolished (Fig. 21).

Redistribution of acid phosphatase following colchicine treatment. To determine whether the effect of colchicine was solely restricted to the redistribution of Dpp II or whether it represented a more generalized phenomenon, we investigated the effect of colchicine on the histochemical localization of acid phosphatase. All neurons which contain acid phosphatase also contain Dpp II, although not in the same relative concentration. Within neurons, acid phosphatase staining was observed in cell nuclei, cytoplasm, and, to a lesser extent, dendrites. A major difference in the cell pattern of distribution of these two enzymes is the large number of uniformly distributed glial cells which are only positive for acid phosphatase.

Following a $100-\mu \mathrm{g}$ i.c.v. injection of colchicine there is a rapid intracellular redistribution of acid phosphatase reaction product. This effect can be clearly observed in the dentate nucleus of the cerebellum (Figs, 24 and 25); somal staining is completely abolished, whereas dendritic staining is markedly enhanced. As was the case for Dpp II, colchicine does not produce a redistribution of acid phosphatase in neurons of the mesencephalic nucleus of the trigeminal nerve. This suggests that colchicine may be stimulating the transport of these two enzymes into dendrites through similar mechanisms.

In vitro effect of colchicine on Dpp /I activity. To determine whether the redistribution of Dpp II was a result of a direct interaction of colchicine with Dpp II, we investigated whether colchicine had a direct inhibitory effect on the enzymatic activity of Dpp II. Soluble brain extracts were treated with concentrations of colchicine equivalent to those used in vivo, and the effect on the enzymatic activity of Dpp II was measured fluorometrically. Table I shows that concen- 

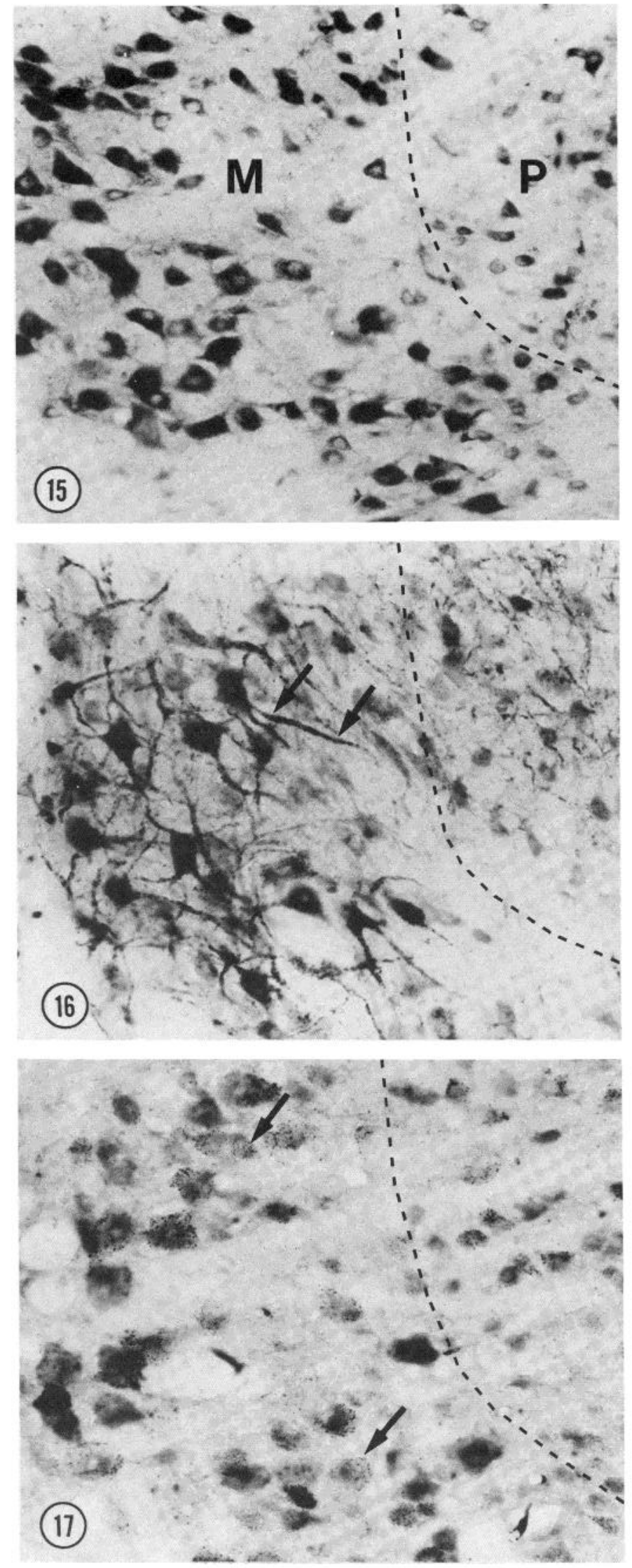

Figures 15 and 16. Sagittal sections through the red nucleus of a rat showing magnocellular and parvocellular neurons (demarcated by dashed lines). Figure 15 shows the normal distribution of Dpp II in somata of both trations as high as $300 \mu \mathrm{g} / \mathrm{ml}$ of colchicine do not significantly affect the activity of Dpp II.

\section{Discussion}

Our main finding is the paradoxical effect which colchicine has on the intracellular distribution of two enzymes: Dpp II and acid phosphatase. Injections of colchicine into the lateral cerebral ventricles, known to produce a blockade of axonal and dendritic transport, produce a rapid and reversible translocation of these enzymes from their normal localization in the cell body to the dendrites. Although there is overwhelming evidence to indicate that colchicine has a profound inhibitory effect on the transport of many cellular constituents (Grafstein and Forman, 1980; Ochs, 1984), this study demonstrates that colchicine can, either directly or indirectly, stimulate the transport of certain lysosomal enzymes in neurons and suggests that enzyme translocation may be the result of a somatofugal movement of lysosomes from the cell body to the dendrites.

Dpp II and acid phosphatase are ubiquitous enzymes found in a large number of organs and cell types (Lojda et al., 1979). Both enzymes have an acid pH optimum and are thought to be localized mainly to lysosomes (Smith, 1969; Smith and Van Frank, 1975; Sannes et al., 1979). In the brain the histochemical distributions of acid phosphatase and Dpp II are very similar. All populations of neurons which contain Dpp II also contain acid phosphatase. However, major differences are observed in glial cells which only contain acid phosphatase. In neurons Dpp II and acid phosphatase are predominantly found in the cell body with comparatively little staining in dendrites. The physiological roles of acid phosphatase and Dpp II are unclear. In the brain, both of these enzymes display a highly localized distribution (Koenig, 1969; Gorenstein et al., 1981), suggestive of unique metabolic functions.

Following colchicine treatment there is a rapid redistribution of Dpp II from the cell body to the dendrites. As early as $1 \mathrm{hr}$ following a colchicine injection it is possible to see this effect (Fig. 2). This is striking in view of the distance separating the site of injection and some of the neuronai pupulations affected. This rapid action indicates that colchicine from the cerebrospinal fluid rapidly equilibrates in brain tissue.

The response of different neuronal populations to colchicine varies. In the olfactory bulb it is possible to observe patches of mitral cells displaying intense dendritic staining adjacent to areas where only somal staining is visible (not shown). This is most likely the result of uneven diffusion of colchicine throughout the olfactory bulb, since it is the cells most distant from the site of injection which display the somal staining. In other neuronal populations the effect of colchicine is also heterogeneous. For example, in Purkinje cells of the cerebellum (Fig. 8), the nucleus ambiguus (Fig. 10), and the red nucleus (Fig. 16), both somal and dendritic staining are observed, whereas in the superior olivary complex (Figs. 13 and 14) and the lateral reticular nucleus of the medulla (Fig. 20), somal staining is virtually absent and dendritic staining is pronounced.

The redistribution of Dpp II following colchicine treatment is dose dependent and reversible. At low doses of colchicine $(25 \mu \mathrm{g})$ neurons display mainly somal Dpp II staining (Fig. 19), whereas at the highest dose used $(400 \mu \mathrm{g})$ Dpp II reaction product is exclusively localized in dendrites (Fig. 21). When rats are allowed to recover for 5 days after a $100-\mu \mathrm{g}$ injection of colchicine there is a reduction in

magnocellular $(M)$ and parvocellular $(P)$ neurons. Figure 16 shows the effect of a $100-\mu \mathrm{g}$ colchicine injection with a survival time of $24 \mathrm{hr}$. Magnocellular neurons (left) show intense somal as well as dendritic (arrows) Dpp II staining whereas parvocellular neurons (right) show mainly dendritic staining. Mag nification $\times 175$ for Figures 15 and 16

Figure 17. Recovery from colchicine treatment. Rats were injected i.c.v. with $100 \mu \mathrm{g}$ of colchicine and were sacrificed 5 days later. A sagittal section through the red nucleus indicates that both magnocellular and parvocellular neurons contain punctate Dpp $\|$ reaction product exclusively in cell bodies (arrows). Magnification $\times 175$. 

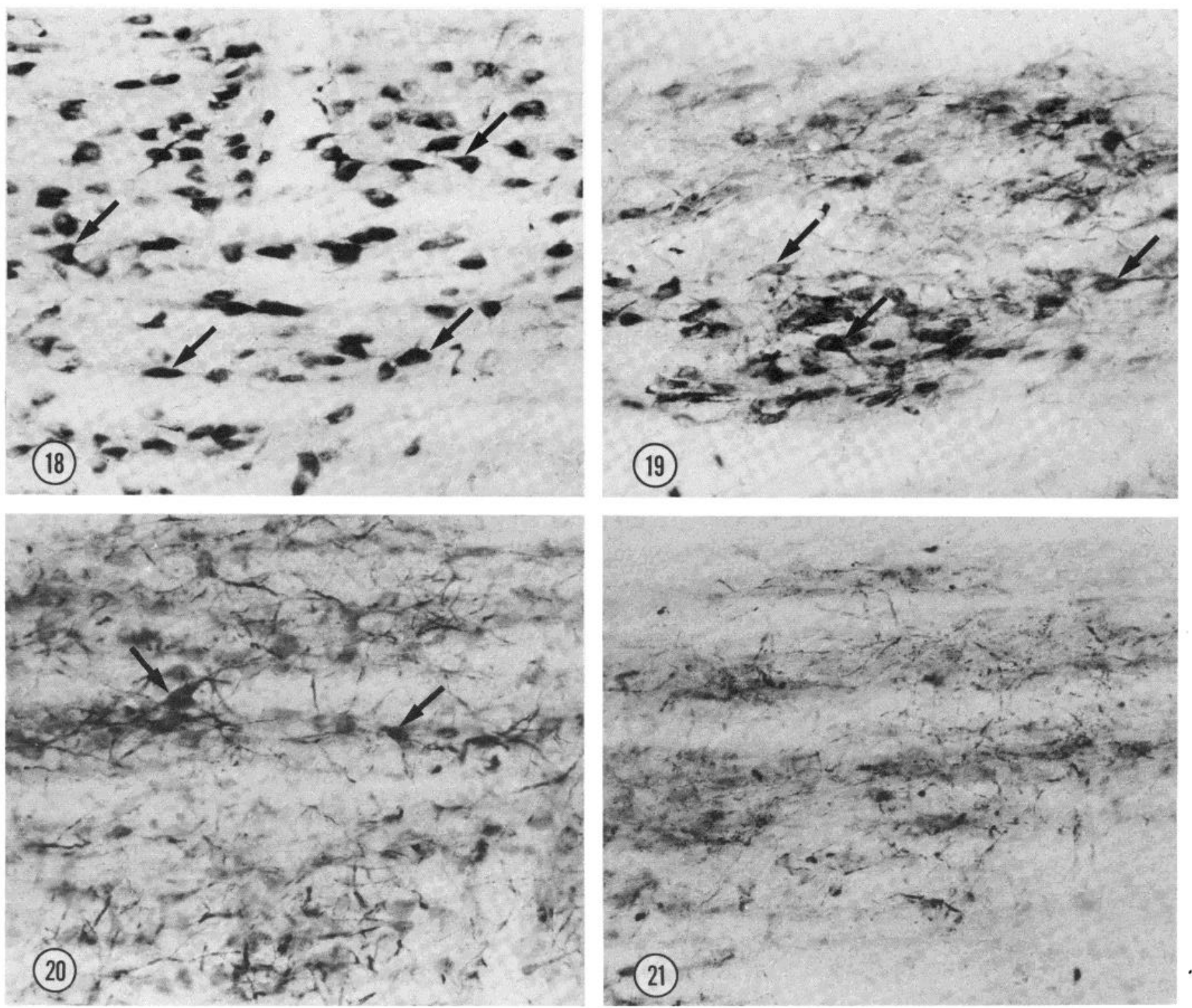

Figures 18 to 21. Effect of different dosages of colchicine on the histochemical distribution of Dpp II in the lateral reticular nucleus of the medulla. Animals were injected i.c.v. with various doses of colchicine and were sacrificed $24 \mathrm{hr}$ later. Figure 18 shows Dpp II-labeled somata (arrows) in a control preparation. Figure 19 shows the effect of a 25- $\mu \mathrm{g}$ colchicine injection. Significant numbers of cell bodies still show Dpp II staining (arrows), but dendritic staining is also prominent. Figure 20 shows the effect of a $100-\mu \mathrm{g}$ colchicine injection. Most of the Dpp II activity is now in dendrites with only a few cell bodies remaining labeled (arrows). Figure 21 shows the effect of a $400-\mu \mathrm{g}$ colchicine injection. Note the complete absence of cell bodies containing Dpp II. Only dendrites containing Dpp II are visible. Magnification $\times 175$ for Figures 18 to 21 .

the amount of somal labeling and an absence of dendritic staining (Fig. 17), indicating a return to the normal pattern of Dpp II staining. Examination of these neurons shows that the Dpp II reaction product is more punctate in nature (Fig. 17) than that observed in control preparations, and probably represents a less aggregated form of Dpp II reaction product. We presently do not know whether the staining observed in these cells represents newly made enzyme or enzyme transported in retrograde fashion from the dendrites.

Injections of colchicine directly into various brain areas have been shown to be neurotoxic and to produce cell loss. This effect is most pronounced in the granule cells of the olfactory bulb, hippocampus, and cerebellum (Goldschmidt and Steward, 1982). Although we have also observed a loss of granule cells in the olfactory bulb in response to i.c.v. injections of colchicine (cf. Figs. 5 and 6), we have not observed an equivalent loss of neurons from the mitral cell layer. Also, we did not observe a significant loss of neuronal cell bodies in the red nucleus (Fig. 17) or in other Dpp II-containing cells examined 5 days after a colchicine injection. Thus, we conclude that the redistribution of Dpp $\|$ is not accompanied by a loss of neuronal cell bodies which contain the enzyme.

Colchicine not only produces a redistribution of Dpp I| but, in addition, appears to lower the total level of Dpp \| activity in some brain regions as visualized by histochemical methods. This can be seen in Figures $3,4,13,14$, and 21 . One possible explanation is that colchicine inhibits Dpp II directly. This is apparently not the case since concentrations of colchicine as high as $300 \mu \mathrm{g} / \mathrm{ml}$ (equivalent to an i.c.v. injection of $600 \mu \mathrm{g}$ of colchicine) did not produce a significant reduction in the in vitro activity of the enzyme (Table I). Since colchicine has been reported to disrupt vesicle and enzyme transport from the Golgi apparatus to the plasma membrane (Hindelang-Gertner et al., 1976; Odam and Ikehara, 1981; Redman et al., 1981), we suggest that the reduction in Dpp II activity observed 

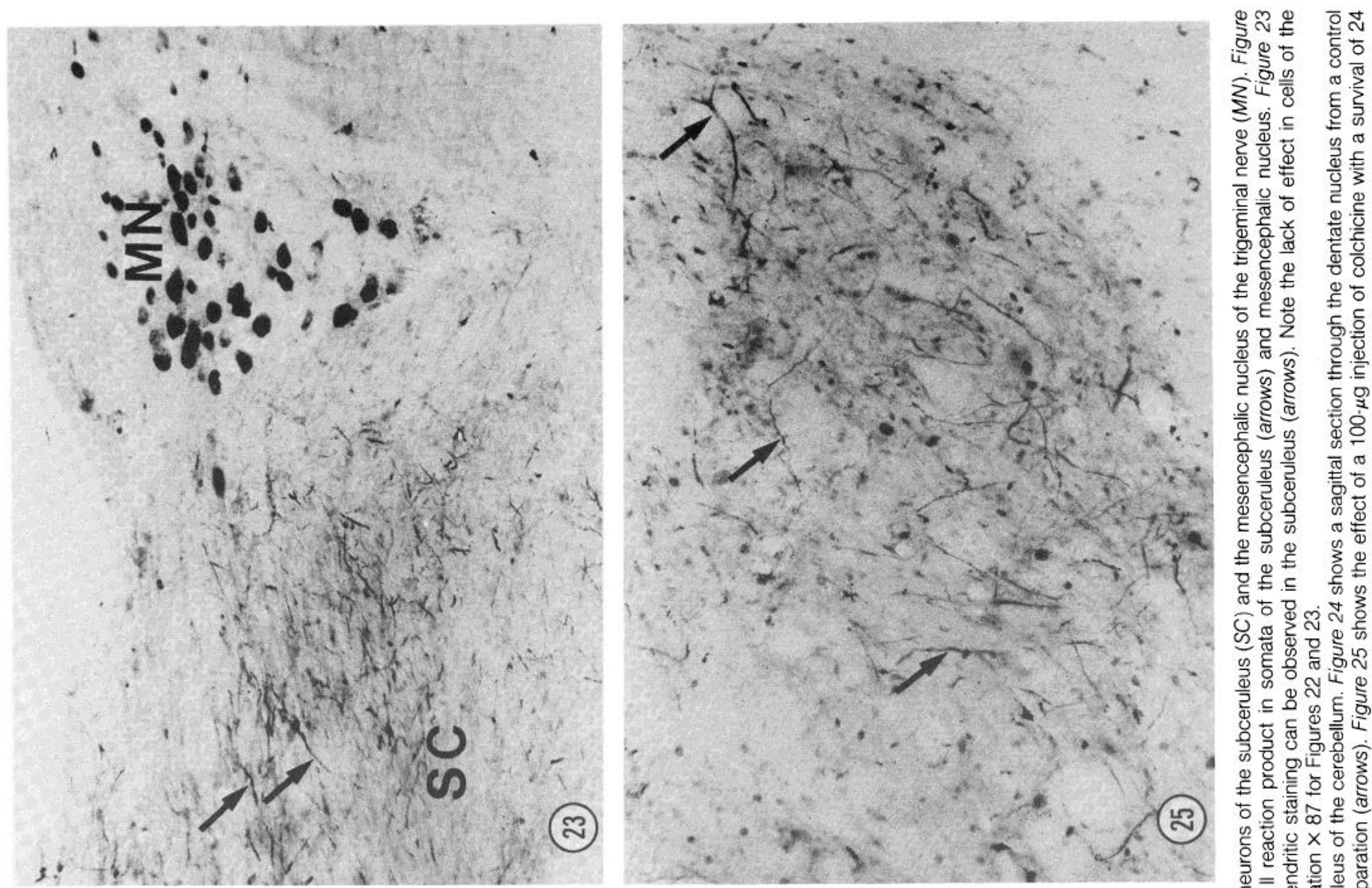

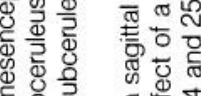

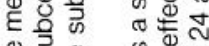

के

동.5 क क क

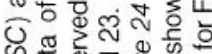

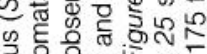

क्ष

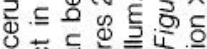

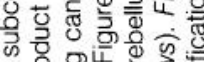

岳

t。

นै. $0 \times 40$

政

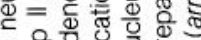

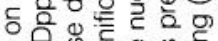
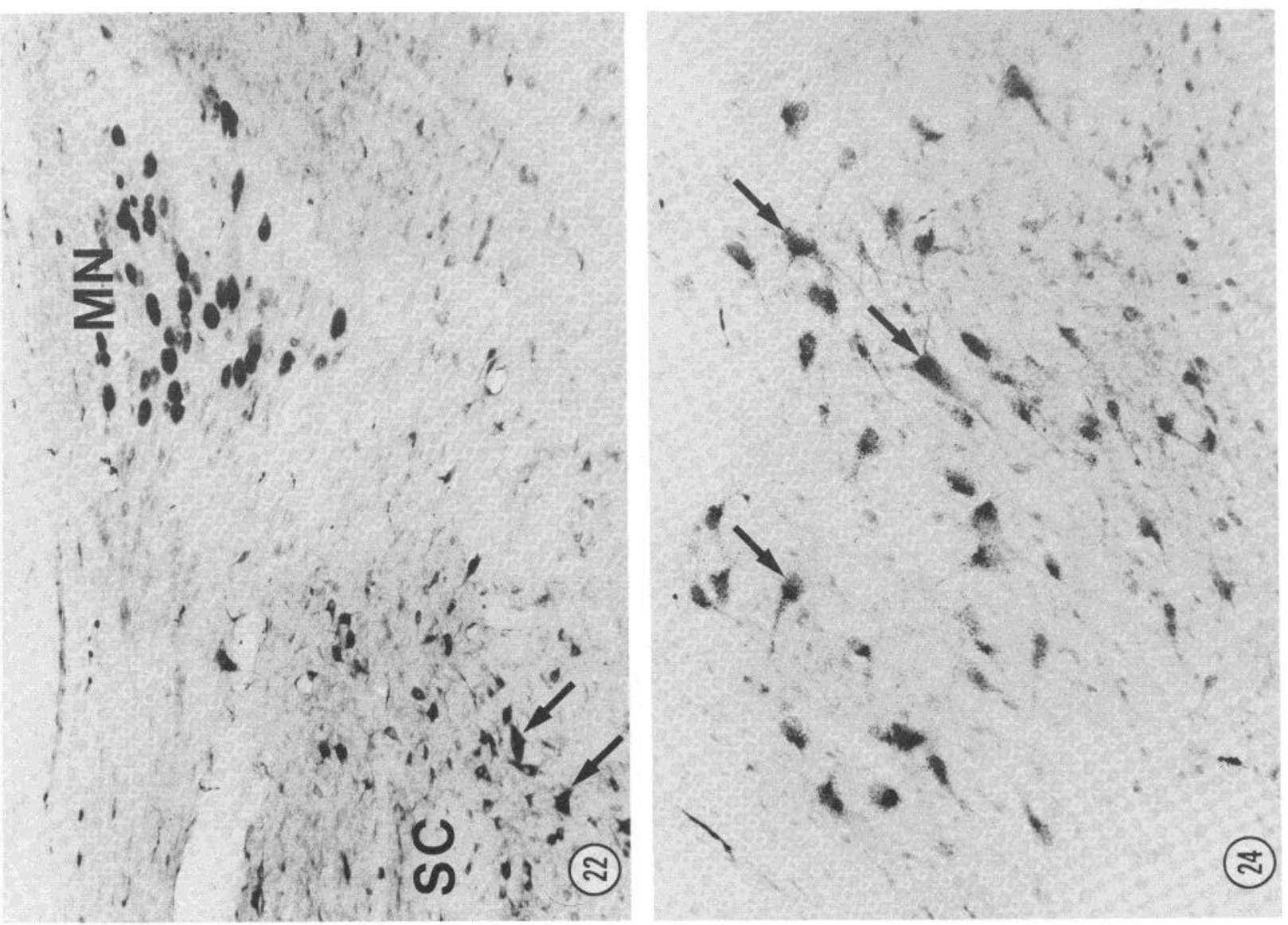

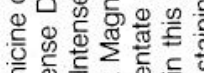

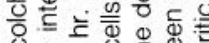

证定

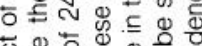

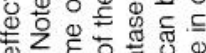

당

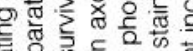

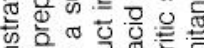

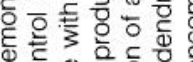

응 응

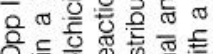

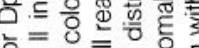

응응응

형등응동동

需

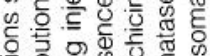

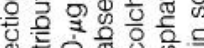

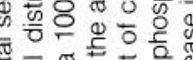

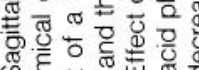

क ह

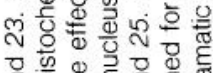

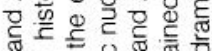

స

(

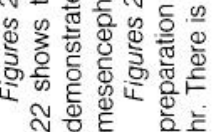


TABLE ।

In vitro effect of colchicine on the activity of Dpp II

Brain extracts, prepared as described under "Materials and Methods," were incubated with varying concentrations of colchicine, and the activity of Dpp II was measured fluorometrically using Lys-Ala-NA as the substrate. One hundred percent activity represents the hydrolysis of $1 \mathrm{mmol}$ of Lys-Ala-NA/ Inin $/ 10-\mu$ l brain extract at $37^{\circ} \mathrm{C}$.

\begin{tabular}{cc}
$\begin{array}{c}\text { Colchicine } \\
(\mu \mathrm{g} / \mathrm{ml})\end{array}$ & $\begin{array}{c}\text { Percentage } \\
\text { of } \\
\text { Dpp II Activity }\end{array}$ \\
\hline 0 & 100 \\
10 & 96 \\
20 & 97 \\
50 & 95 \\
100 & 96 \\
300 & 92 \\
\hline
\end{tabular}

may be related to an interference with the passage of Dpp II from the Golgi apparatus to primary lysosomes.

Colchicine-induced translocation of Dpp II and acid phosphatase occurs in all neurons which contain these enzymes, except in those of the mesencephalic nucleus of the trigeminal nerve (Fig. 23). Somal staining of Dpp $\|$ in these cells is unaffected even though nearby populations of neurons in the subceruleus show intense dendritic staining. Neurons of the mesencephalic nucleus of the trigeminal nerve are pscudo-unipolar and thus do not contain dendrites. The absence of dendritic staining is therefore expected; however, the absence of significant Dpp II reaction product in axons indicates that the effect of colchicine is restricted to the translocation of lysosomal enzymes into dendrites. This conclusion is also consistent with the absence of axonal staining in other neuronal populations. In addition, the presence of somal staining in these cells indicates that colchicine does not lead to an accumulation of substances in the cell body which may inhibit the activity of Dpp II or acid phosphatase.

In addition to colchicine, we tested the ability of other cytoskeletal specific drugs to produce a translocation of Dpp $\|$ from the cell body to the dendrites. Vincristine and podophylotoxin, potent inhibitors of microtubule-mediated transport (Banks and Till, 1975), produced a redistribution of enzymes virtually indistinguishable from that observed with colchicine (unpublished observation). In contrast, lumicolchicine, an inactive analogue of colchicine, was without effect (unpublished observation). It is tempting to conclude from the evidence presented that microtubules maintain lysosomal enzymes in the cell body, and inhibition of microtubule polymerization by colchicine stimulates a translocation of these organelles into the dendrites. In the following paper (Gorenstein and Ribak, 1985) we investigate this possibility by examining this phenomenon at the electron microscopic level.

\section{References}

Banks, P., and R. Till (1975) A correlation between the effects of antimitotic drugs on microtubule assembly in vitro and the inhibition of axonal trainsport in noradrenergic neurons. J. Physiol. (Lorid.) 252: 283-294.

Burgoyne, R. D., and R. Cumming (1983) Characterization of microtubule associated proteins at the synapse: Absence of MAP2. Eur. J. Cell Biol 30: $154-158$.

Cumming, R., and R. D. Burgoyne (1983) Compartmentalization of neuronal cytoskeletal proteins. Biosci. Rep. 3: 997-1006.

Dahlstrom, A. (1968) Effect of colchicine on transport of amine storage granules in sympathetic neurons of the rat. Eur. J. Pharmacol. 5: 111-113.

Fonnum, F., M. Frizell, and J. Sjostrand (1973) Transport, turnover and distribution of choline acetyltransferase and acetylcholinesterase in the vagus and hypoglossal nerves of the rabbit. J. Neurochem. 21: 11091120 .
Globus, A., H. D. Lux, and P. Schubert (1968) Somatodendritic spread of intracellularly injected tritiated glycine in cat spinal motoneurons. Brain Res. 11: 440-445.

Goldschmidt, R. B., and O. Steward (1982) Neurotoxic effects of colchicine Differential susceptibility of CNS neuronal populations. Neuroscience 7 : 695-714.

Gomori, G. (1952) Microscopic Histochemistry: Principles and Practice, University of Chicago Press, Chicago.

Gorenstein, C., and C. E. Ribak (1985) Dendritic transport. II. Somatofugal movement of neuronal lysosomes induced by colchicine: Evidence for a novel transport system in dendrites. J. Neurosci. 5: 2018-2027.

Gorenstein, C., V. T. Tran, and S. H. Snyder (1981) Brain peptidase with a unique neuronal localization: The histochemcial distribution of dipeptidylaminopeptidase II. J. Neurosci. 1: 1096-1102.

Grafstein, B., and D. S. Forman (1980) Intracellular transport in neurons. Physiol. Rev. 60: 1167-1283.

Hindelang-Gertner, C., M. Stoeckel, A. Porte, and F. Stutinsky (1976) Colchicine effects on neurosecretory neurons and other hypothalamic and hypophysial cells, with special reference to changes in the cytoplasmic membranes. Cell Tissue Res. 170: 17-41

Innis, R. B., F. M. A. Correa, G. R. Uhl, B. Schneider, and S. H. Snyder (1979) Cholecystokinin octapeptide-like immunoreactivity: Histochemical localization in rat brain. Proc. Natl. Acad. Sci. U. S. A. 76:521-525.

James, K. A. C.. J. J. Bray, I. G. Morgan, and L. Austin (1970) The effects of colchicine on the transport of axonal protein in the chicken. Biochem. J. 117: 767-771.

Kiss, J. (1977) Synthesis and transport of newly formed proteins in dendrites of rat hippocampal pyramid cells. An electron microscope autoradiographic study. Brain Res. 124: 237-250.

Koenig, H. (1969) Lysosomes in the nervous tissue. In Frontiers of Biology: Lysosomes in Biology and Pathology, J. T. Dingle and H. B. Fell, eds. Vol. 14B, pp. 111-162, Elsevier-North Holland Publishing Co., Amsterdam.

Koning, J. F. R., and R. A. Klippel (1963) The Rat Brain. A Stereotaxic Atlas of the Forebrain and Lower Parts of the Brain Stem, Robert E. Krieger Publishing Co., Huntington, NY.

Kreutzberg, G. W., and P. Schubert (1973) Neuronal activity and axonal flow. In Central Nervous System Studies on Metabolic Regulation and Function, E. Genazzani and H. Herken, eds., pp. 84-93, Springer-Verlag. Berlin.

Kreutzberg, G. W., and P. Schubert (1975) The cellular dynamics of intraneuronal transport. In The Use of Axonal Transport for Studies of Neurona Connectivity, W. M. Cowan and M. Cuenod, eds., pp. 83-112, ElsevierNorth Holland Publishing Co., Amsterdam.

Lojda, Z., R. Gossrau, and T. H. Schiebler (1979) Enzyme Histochemistry, Springer-Verlag, Berlin.

Lynch, G., R. L. Smith, M. D. Browning, and S. Deadwyler (1975) Evidence for bidirectional dendritic transport of horseradish peroxidase. Adv. Neurol. 12: $297-311$

Ochs, S. (1984) Axoplasmic Transport and Its Relation to Other Nerve Functions, John Wiley \& Sons, Inc., New York.

Odam, K., and $Y$. Ikehara (1981) Inhibitory effect of colchicine on translocation of alkaline phosphatase to the plasma membrane concomitant with its induction in rat liver. Biochim. Biophys. Acta 640:398-408.

Redman, C. M., D. Banerjee, and S. Yu (1981) The effect of colchicine on the synthesis and secretion of rat serum albumin. Methods Cell Biol. 23: $231-245$

Ribak, C. E., J. E. Vaughn, and K. Saito (1978) Immunocytochemical localization of glutamic acid decarboxylase in neuronal somata following colchicine inhibition of axonal transport. Brain Res. 140: 315-332.

Sannes, P. L., J. K. McDonald, R. C. Allen, and S. S. Spicer (1979) Cytochemical localization and biochemical characterization of dipeptidyl aminopeptidase $\|$ in macrophages and mast cells. J. Histochem. Cytochem. 27: 1496-1498.

Schubert, P., G. W. Kreutzberg, and H. D. Lux (1972) Neuroplasmic transport in dendrites: Effect of colchicine on morphology and physiology on motoneurons in the cat. Brain Res. 47: 331-343.

Smith, R. E. (1969) Phosphohydrolases in cell organelles: Electron microscopy. Ann. N. Y. Acad. Sci. 166: 525-564.

Smith, R. E., and R. M. Van Frank (1975) The use of amino acid derivatives of 4-methoxy-beta-naphthylamine for the assay and subcellular localization of tissue proteinases. In Frontiers of Biology: Lysosomes in Biology and Pathology, J. T. Dingle and R. T. Dean, eds., Vol. 43, pp. 193-249, Elscvier-North Holland Publishing Co., Amsterdam. 